\title{
Multi-decadal mass loss of glaciers in the Everest area (Nepal Himalaya) derived from stereo imagery
}

T. Bolch ${ }^{1,3}$, T. Pieczonka ${ }^{1}$, and D. I. Benn ${ }^{2,4}$

${ }^{1}$ Institut für Kartographie, Technische Universität Dresden, Germany

${ }^{2}$ The University Centre in Svalbard, Norway

${ }^{3}$ Geographisches Institut, Universität Zürich, Switzerland

${ }^{4}$ School of Geography and Geosciences, University of St Andrews, UK

Correspondence to: T. Bolch (tobias.bolch@geo.uzh.ch)

\section{Supplementary Figures}
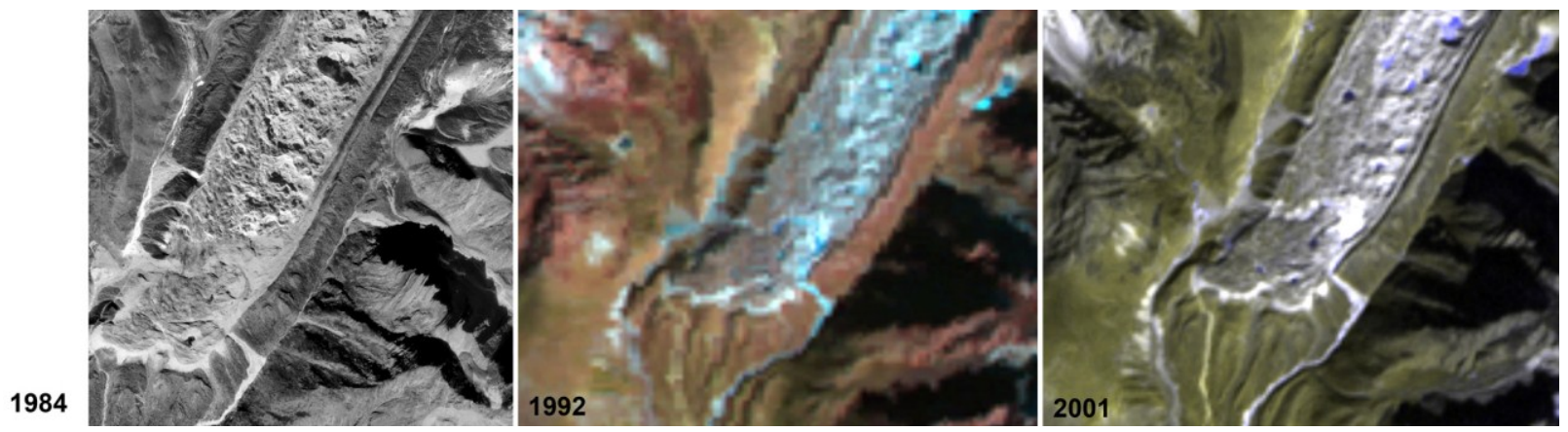

Figure 1: The terminus of Khumbu Glaciers based on the 1984 aerial image, 1992 Landsat TM, and 2001 ASTER Data.

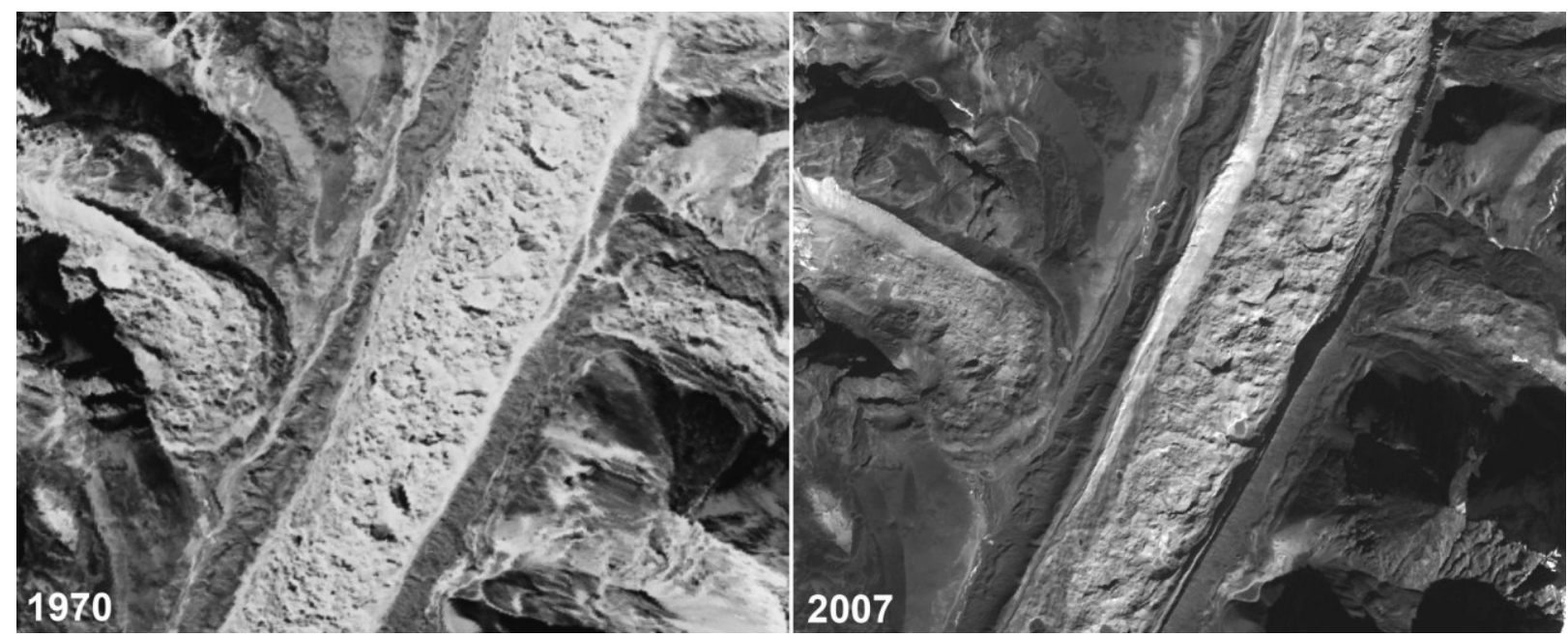

Figure 2: Central part of the tongue of Khumbu Glacier based on the 1970 Corona and 2007 Cartosat-1 image. 


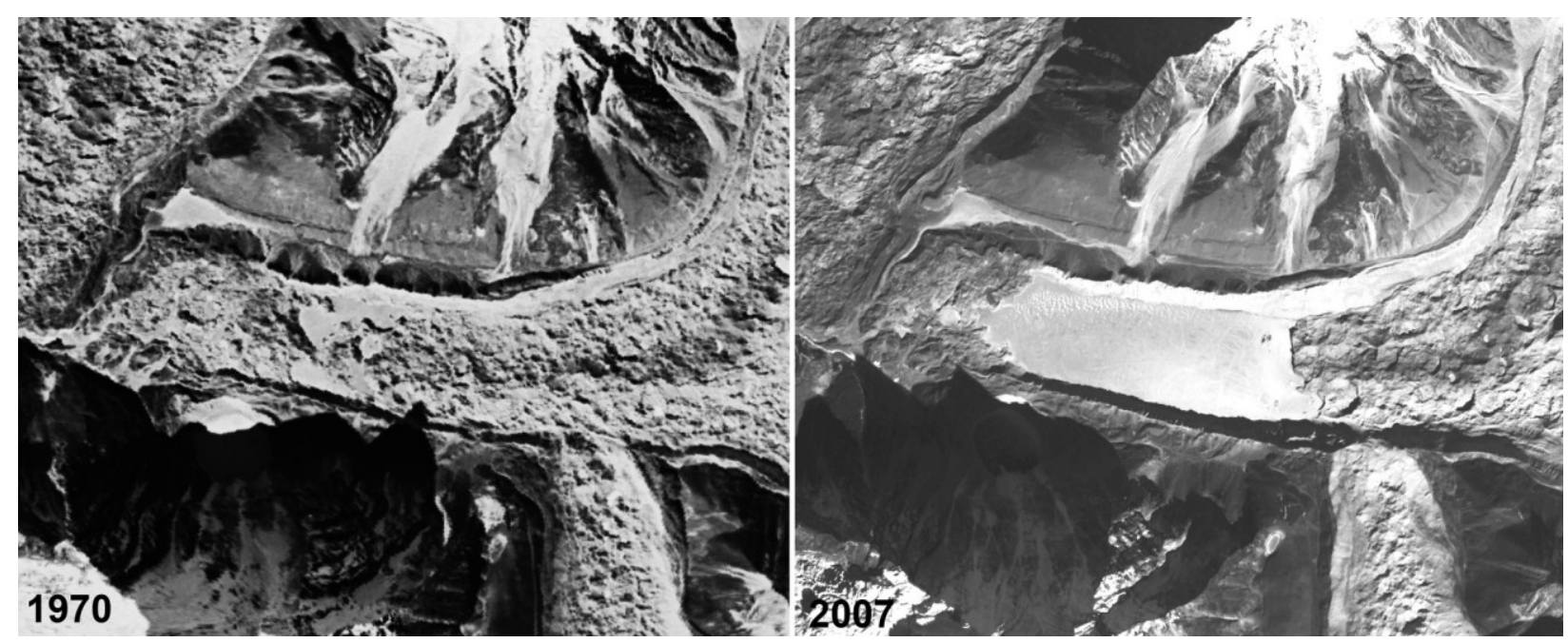

Figure 3: Termini of Imja and Amphu Laptse glaciers showing also the occurrence of the Imja Lake based on the 1970 Corona and 2007 Cartosat-1 image. Amphu Laptse Glacier did probably not anymore contribute to Imja Glacier in 2007.
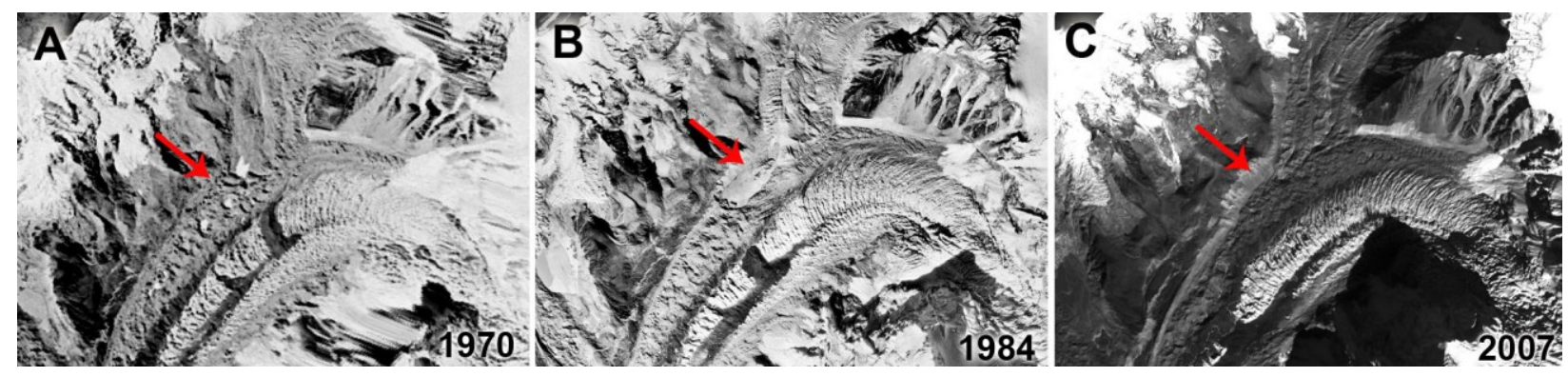

Figure 4: Upper tongue of Khumbu Glacier below the Khumbu ice fall based on the 1970 Corona, 1984 Wild RC-10 and 2007 Cartosat- 1 image. The red arrows indicate where a lake developed between 1970 and 1984 which drained afterwards. 